\title{
Prevalence of Asthma and Allergic Rhinitis in Children with Celiac
} Disease

\author{
Sebnem Ozdogan, ${ }^{1,}{ }^{*}$ Nafiye Urganci, ${ }^{2}$ Merve Usta, ${ }^{2}$ and Nuray Uslu Kizilkan ${ }^{2}$ \\ ${ }^{1}$ Pediatric Pulmonology, Sisli Hamidiye Etfal Research and Training Hospital, Istanbul, Turkey \\ ${ }^{2}$ Pediatric Gastroenterology, Sisli Hamidiye Etfal Research and Training Hospital, Istanbul,Turkey \\ "Corresponding author: Sebnem Ozdogan, Pediatric Pulmonology, Sisli Hamidiye Etfal Research and Training Hospital, Istanbul, Turkey. E-mail: ozdogan65@hotmail.com
}

Received 2016 April 12; Revised 2016 June 06; Accepted 2016 July 17.

\begin{abstract}
Background: Celiac disease is an autoimmune disorder characterized by damage to the small intestinal mucosa following the intake of glutencontaining foods in genetically predisposed individuals. Studies suggest that celiac disease is associated with asthma and allergic rhinitis.

Objectives: The aim of this study was to examine the prevalence of asthma and allergic rhinitis in children with celiac disease compared to healthy controls.

Methods: This study was conducted in 53 celiac children and 80 children with nonspecific abdominal pain as a control group; all participants were between 6 - 19 years. The children completed the ISAAC questionnaire, and spirometry was performed in each participant.

Results: The prevalence rates of asthma symptoms and physician-diagnosed asthma were similar in both groups (30\% and 19\%, respectively, in the celiac group and $17.5 \%$ and $22.5 \%$, respectively, in the control group) ( $\mathrm{P}>0.05)$. Six (11\%) patients with celiac disease and seven ( $9 \%$ ) children in the control group showed obstructive changes on pulmonary function tests. The prevalence rates of allergic rhinitis symptoms and physician-diagnosed allergic rhinitis were also similar in both groups (36\% and 9\%, respectively, in the celiac group, and $34 \%$ and $9 \%$, respectively, in the control group) (P $>0.05)$.

Conclusions: The prevalence rates of asthma and allergic rhinitis in patients with celiac disease were not significantly higher when compared to the healthy controls.

Keywords: Celiac Disease, Prevalence, Asthma, Allergic Rhinitis, Children
\end{abstract}

\section{Background}

Celiac disease (CD) is an autoimmune disease characterized by damage to the small intestinal mucosa following the intake of gluten-containing foods in genetically predisposed individuals, and its prevalence in the general population is approximately $1 \%$ (1). In a study of children between 6 and 17 years of age in Turkey, the prevalence was reported to be $0.47 \%$ (2). The clinical manifestations (including gastrointestinal and non-gastrointestinal symptoms) of CD may vary. Patients who do not exhibit clinical symptoms but whose serology and small intestine pathology are consistent with CD suggest that the prevalence of the disease may be higher than currently thought.

Asthma is the most commonly seen childhood health condition, and its prevalence is approximately $10 \%$ in Europe and from $9.8-17.8 \%$ in Istanbul, Turkey (3-5). Allergic rhinitis is characterized by paroxysmal sneezing, nasal discharge, and nasal congestion; it is often accompanied by itching of the eyes and nose and has a prevalence of 10 $40 \%$ (6). Although the frequency of allergic rhinitis varies among different countries and regions, a study conducted across Turkey reported the incidence to be $49.4 \%$ in children from 13 - 14 years of age and 17.6\% in those between 6 and 15 years of age in Istanbul $(4,7)$.

In the literature, publications on the relationship be- tween CD and lung diseases go back to the 1970s (8). Previous studies have reported that CD is associated with diffuse lung disease, bird fancier's lung, farmer's lung, sarcoidosis, and cryptogenic fibrosing alveolitis (9-12). An association between CD and atopic diseases was first suggested in 1976 (13). A study published in 1981 by Tarlo et al. suggested that CD is associated with asthma (14).

While CD, which is an autoimmune disease, is associated with $\mathrm{T}$ helper type 1 cell expression, $\mathrm{T}$ helper type 2 cells also play a role in the pathophysiology of allergic diseases, such as asthma. Although only a few studies have investigated the relationship between asthma and autoimmune diseases, their results have not been consistent (1521). Some of these studies have suggested that autoimmune and allergic diseases may occur together depending on common genetic risk factors (15-20). However, the increased incidence of both diseases also points to common environmental risk factors as a possible causative factor (5, $22,23)$.

\section{Objectives}

In the present study, we aimed to evaluate the prevalence of asthma and allergic rhinitis and performed pulmonary function testing (PFT) in children between 6 and 
19 years of age who had been diagnosed with CD compared to children with nonspecific abdominal pain as a control group.

\section{Methods}

This cross-sectional study enrolled 53 patients (21 males and 32 females) from $7-19$ years of age with a CD diagnosis and 80 patients ( 37 males and 43 females) with nonspecific abdominal pain who were followed at our pediatric gastroenterology clinics. During an outpatient visit, the participants were informed about the study, and informed consent was obtained from both the parents and children. The subjects completed a standardized questionnaire form, which gathered their demographic information, and also the ISAAC Questionnaire, which consists of 11 questions related to asthma and allergic rhinitis. The prevalence of accumulated asthma was evaluated using the percentage of affirmative answers to question 1 of the asthma module: "wheezing (at any time)." The prevalence of active asthma was estimated by the percentage of affirmative responses to question 2: "wheezing (in the last 12 months)." The incidence of asthma as diagnosed by a physician was assessed indirectly using the number of affirmative answers to question 6: "asthma at any time in life." The ISAAC Auestionnaire has been validated in Turkish (24). Children who were older than 12 years of age completed the questionnaire by themselves, while those who were younger than 12 received help from their parents.

Following the completion of the questionnaire, a PFT was performed on each participant by the same pediatric pulmonologist. All children who completed the questionnaire and underwent PFTs were included in this study. Figure 1 shows the study flowchart. The body mass index (BMI) was calculated for each participant and was evaluated by age according to four groups: underweight, normal, overweight, and obese (25). Approval for the study was obtained from the Sisli Hamidiye Etfal research and training hospital ethics committee.

\subsection{Pulmonary Function Tests}

Spirometry measurements were taken by the same pediatric pulmonologist. The procedure was performed in accordance with the ATS standards using a spirometer device (MiniSpir ${ }^{\circledR}$ ) purchased from MIR (medical international research Srl, Rome, Italy) (26). The following variables were analyzed: best FEV1, FVC and FEV1/FVC. An FEV1 $<80 \%$ or an FEV1/FVC ratio $<80 \%$ were considered to indicate obstructive changes.

\subsection{Diagnosis of $C D$}

The diagnosis of CD was based on serological testing (IgA and IgG endomysial antibodies (EMA), IgA and IgG gliadin antibodies, and IgA and IgG human tissue transglutaminase antibodies), small bowel biopsy performed during upper endoscopies, and histological evidence of villous atrophy with crypt hyperplasia and an increase in intraepithelial lymphocytes.

\subsection{Adherence to Diet}

Participants were defined as adherent to the diet if they had been followed with a diagnosis of $\mathrm{CD}$ for at least one year, reported that they were compliant with the glutenfree diet, and were negative for the EMA antibody.

\subsection{Statistical Analysis}

Number cruncher statistical system (NCSS) 2007 statistical software (Utah, USA) was used for the statistical analyses. To evaluate the study data, descriptive statistics (mean, standard deviation, median, frequency, and ratio) were calculated, and the Mann-Whitney $U$ test was performed to assess between-group comparisons for non-normally distributed variables. Fisher's exact test, Fisher Freeman Halton test, Yates continuity correction test, and Pearson chi square test were used to compare the qualitative data. Confidence intervals were calculated at the $95 \%$ level, and P values $<0.05$ were considered statistically significant.

\section{Results}

This study investigated 133 participants, including 53 CD patients and 80 children with nonspecific abdominal pain as the control group. The demographic data and clinical characteristics are shown in Table 1 . The mean age was $12.3 \pm 3.62$ years in the $C D$ group and $11.73 \pm 3.6$ years in the control group. A comparison of the two groups with respect to age, gender, anthropometric measurements, and parental history of asthma and allergic rhinitis revealed that the number of children with a weight and height below the 3rd percentile was significantly higher in the $C D$ group ( $\mathrm{P}=0.006$ and $\mathrm{P}=0.003$, respectively). The mean age, gender, BMI values, and parental history of asthma and allergic rhinitis were similar in both groups. The mean follow-up period for CD patients was $54.43 \pm 48.10$ (1 - 180) months. Of the 53 children with $C D, 75 \%(n=40)$ were adherent to the diet, while $74 \%(n=31)$ of those who had been followed for one year or longer followed the diet.

The prevalence of asthma and allergic rhinitis and the PFT results are shown in Table 2. An evaluation of the asthma-related and allergic rhinitis-related questions indicated that there was no statistically significant difference 


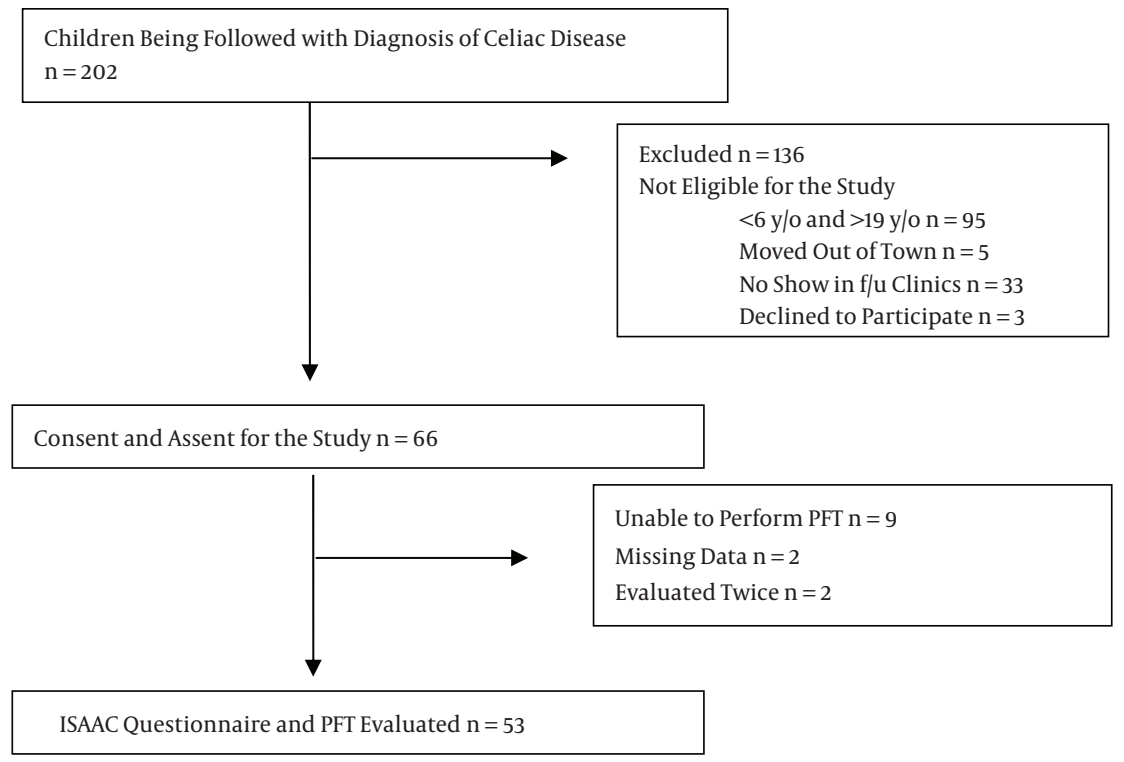

Figure 1. Flow Chart

between the $\mathrm{CD}$ group and the control group. The PFT results of $11 \%(n=6)$ of the patients with CD and $8.8 \%(n=7)$ of the control group were consistent with obstructive pulmonary changes.

The relationship between the follow-up period for the CD group and the presence of asthma and allergic rhinitis symptoms is presented in Table 3. The follow-up period was not associated with asthma symptoms, asthma medication use, allergic rhinitis symptoms, or long-term nasal steroid use $(\mathrm{P}>0.05)$.

In patients with $\mathrm{CD}$ who were followed for at least one year, adherence to a gluten-free diet was assessed according to the participants' PFT results and asthma symptoms (Table 4). Adherence to this diet was not associated with obstructive changes or the presence of asthma symptoms.

\section{Discussion}

In the present study, children between the ages of 6 and 19 years with a diagnosis of CD who completed followup and an age-matched control group were surveyed using the ISAAC questionnaire for asthma and allergic rhinitis; their pulmonary function was measured via a PFT. The prevalence rates of asthma and allergic rhinitis in patients with CD were not significantly higher when compared to the control group.

Increasing attention is being paid to the association between autoimmune and allergic diseases. Studies on this relationship have shown that the two disease groups may be seen concomitantly, although their pathophysiology differs; however, it is unclear how they affect each other. Previous studies have suggested that neither causes the other, but they may be seen concomitantly (16-18). A cohort study conducted in Switzerland compared 28,281 patients with CD to 140,295 people without CD; the hazard ratio of asthma for those with vs. those without $C D$ was 1.61 (95\% CI: 1.50 - 1.72) (17). A study that investigated subsequent hospitalization due to an autoimmune disease in 148,295 patients who had been previously hospitalized with asthma reported that $2 \%$ of the patients were hospitalized with an autoimmune diagnosis; the standardized incidence rate of hospitalization with a diagnosis of CD was 1.97 (95\% CI:1.64 - 2.34). It has been suggested that CD is predominantly diagnosed in young patients with asthma. It has also been speculated that the concomitant occurrence of asthma and autoimmune diseases may be due to common genetic factors and possible environmental risk factors (17). Kero et al. reported that the relative risk of asthma was 7.26 (95\% CI: 4.49 - 11.01) in 114 children with CD (18). Zauli et al. suggested that CD is associated with atopy and found the prevalence of celiac disease to be $1 \%$ in an Italian population of atopic patients. They concluded that atopy is a risk for developing $\mathrm{CD}$ and atopic patients should be evaluated for $\mathrm{CD}$ (27). Compared to the findings of previous prevalence studies of healthy children in this region, the rates of asthma and allergic rhinitis symptoms and of physician-diagnosed asthma and allergic rhinitis were higher in our study. However, there was no significant dif- 
Table 1. Demographic Data and Clinical Characteristics of the Participants ${ }^{\mathrm{a}}$

\begin{tabular}{|c|c|c|c|}
\hline & CD Group, $n=53$ & Control Group & CD Group, $n=53$ \\
\hline Age & & & $0.815^{\mathrm{C}}$ \\
\hline Mean \pm SD & $12.30 \pm 3.62$ & $11.73 \pm 3.6$ & \\
\hline Min - max (median) & $6-19(12)$ & $6-19(11)$ & \\
\hline Gender, No. (\%) & & & $0.565^{\mathrm{D}}$ \\
\hline Female & $32(60.4)$ & $43(53.8)$ & \\
\hline Male & $21(39.6)$ & $37(46.3)$ & \\
\hline \multicolumn{4}{|l|}{ Age at diagnosis, y } \\
\hline Mean \pm SD & $7.5 \pm 4.2$ & & \\
\hline Min - max & $1-16$ & & \\
\hline \multicolumn{4}{|l|}{ Follow-up period, $\mathbf{m}$} \\
\hline Mean \pm SD & $54.43 \pm 48.10$ & & \\
\hline Min - max & $1-180$ & & \\
\hline Weight percentile & & & $0.006^{\mathrm{D}, * *}$ \\
\hline$<3$ p, No. $(\%)$ & $13(24.5)$ & $5(6.3)$ & \\
\hline Height percentile & & & $0.003^{\mathrm{B}, * *}$ \\
\hline$<3$ p, No. $(\%)$ & $10(18.9)$ & $2(2.5)$ & \\
\hline BMI & & & $0.343^{\mathrm{C}}$ \\
\hline Underweight & $13(24.5)$ & $10(12.5)$ & \\
\hline Normal weight & $33(62.3)$ & $56(70)$ & \\
\hline Overweight & $5(9.4)$ & $10(12.5)$ & \\
\hline Obese & $2(3.8)$ & $4(5.0)$ & \\
\hline Adherence to a gluten-free diet in patients being $\mathbf{f} / \mathbf{u} \geq 1$ year, $n=42$, No. (\%) & $31(74)$ & & \\
\hline Parental h/o asthma, No. (\%) & $10(18.9)$ & $27(33.8)$ & $0.093^{\mathrm{D}}$ \\
\hline Parental h/o allergic rhinitis, No. (\%) & $15(28)$ & $17(21.3)$ & $0.469^{\mathrm{D}}$ \\
\hline
\end{tabular}

${ }^{\mathrm{a} B}$, Fisher's exact test; C, Student t test; D, Yates Continuity Correction; E, Fisher Freeman Halton test; *** $\mathrm{P}<0.01 ;{ }^{*} \mathrm{P}<0.05$.

ference in the rates of asthma and allergic rhinitis symptoms and physician-diagnosed asthma and allergic rhinitis in $\mathrm{CD}$ patients compared with the control group. The fact that the participants had not yet been diagnosed despite having symptoms of asthma and allergic rhinitis suggests that they were not sufficiently evaluated for atopic diseases.

In our study, when the subjects were queried for asthma symptoms, the prevalence of wheezing attacks at any time, wheezing attacks within the last 12 months, and exercise-induced wheezing, the rates of physiciandiagnosed asthma for each of these symptoms were found to be $30 \%, 17 \%, 17 \%$, and $19 \%$ in CD patients, respectively. These rates are similar to those reported by the control group but are higher than those reported in a study conducted by Ones et al. in children aged 6-12 years in Istanbul
(25.3\%, 11.3\%, 7.6\%, and 17.8\%, respectively) (5). These findings support the rising trend in the prevalence of asthma (Akinbami LJ, Moorman JE, Bailey C, Zahran HS, King M, Johnson CA, Liu X. Trends in asthma prevalence, health care use, and mortality in the United States, 2001-2010. NCHS data brief. 2012;94:1-8).

In our study, although approximately $25 \%$ of CD patients were taking inhaled corticosteroids (ICS), montelukast, or both, only $19 \%$ had been diagnosed with asthma. This result suggests that the children's families were not informed about the diagnosis of asthma. The prevalence rates of physician-diagnosed asthma and allergic rhinitis in the parents of CD patients were $19 \%$ and $28 \%$, respectively and are similar to the mean rates in the control group; they are also greater than the mean rates in Turkey (28). 
Table 2. The Prevalence of Asthma and Allergic Rhinitis and PFT Evaluations in CD Patients Compared to Controls

\begin{tabular}{|c|c|c|c|}
\hline & CD Group, $n=53$, No. $(\%)$ & Control Group, $\mathbf{n}=\mathbf{8 0}$, No. (\%) & P Value \\
\hline Wheezing (at any time) & $16(30.2)$ & $14(17.5)$ & $0.082^{\mathrm{a}}$ \\
\hline Wheezing (in the last 12 months) & $9(17)$ & $6(7.5)$ & $0.158^{\mathrm{a}}$ \\
\hline Exercise-induced wheezing & $9(17)$ & $15(18.8)$ & $0.977^{\mathrm{a}}$ \\
\hline Current use of asthma medication & $13(24.5)$ & $11(13.8)$ & $0.176^{\mathrm{a}}$ \\
\hline Nighttime coughing & $9(17)$ & $19(23.8)$ & $0.471^{\mathrm{a}}$ \\
\hline Physician-diagnosed asthma & $10(18.9)$ & $18(22.5)$ & $0.775^{\mathrm{a}}$ \\
\hline Allergic rhinitis & $19(35.8)$ & $27(33.8)$ & $0.950^{\mathrm{b}}$ \\
\hline Allergic rhinoconjunctivitis & $14(26.4)$ & $27(33.8)$ & $0.481^{\mathrm{a}}$ \\
\hline Nasal steroid use ( $>2$ weeks) & $11(20.8)$ & $20(25.0)$ & $0.721^{\mathrm{a}}$ \\
\hline Physician-diagnosed allergic rhinitis & $5(9.4)$ & $7(8.8)$ & $1.000^{\mathrm{b}}$ \\
\hline \multicolumn{4}{|l|}{ Pulmonary function tests } \\
\hline Normal & 47 & 88.7 & \\
\hline Obstructive changes & $6(11.3)$ & $7(8.8)$ & $0.849^{a}$ \\
\hline
\end{tabular}

${ }^{a}$ Yates continuity correction.

${ }^{\mathrm{b}}$ Fisher's exact test.

Eleven percent of $C D$ patients presented with obstructive changes on their PFTs, which was similar to the rate in the control group. Because we were unable to locate any literature on the relationship between PFT results and CD, no comparison could be made between our findings and those of other studies.

Our evaluation of allergic rhinitis revealed that the rates of allergic rhinitis, allergic rhinoconjunctivitis, and physician-diagnosed rhinitis were $36 \%, 26 \%$, and $9 \%$, respectively, and were similar to the mean rates in the control group. When we compared our results to those of an agematched study conducted in the same region, the prevalence of allergic rhinitis was $17.6 \%$ (4), which is lower than that found in the present study. In our study, two-thirds of the participants who reported rhinitis symptoms were taking nasal steroids, while only one-fourth had been diagnosed with allergic rhinitis; our findings were similar regarding asthma. Therefore, we believe that both pediatric gastroenterologists and pediatricians who follow patients with CD need to have a greater awareness of allergic rhinitis and asthma.

We were unable to establish a correlation between the follow-up period and the prevalence of asthma and allergic rhinitis in CD patients. One study speculated that an adult who was followed after developing bronchiectasis suffered from CD; his/her pulmonary symptoms regressed with a gluten-free diet (29). Ellul et al. suggested that asthma symptoms can be improved with a gluten-poor diet (15). Their study, which was conducted in 86 CD patients liv- ing on the Maltese Islands, found that the prevalence of asthma in the study population was $27.8 \%$ but only $11.1 \%$ in the general population. A gluten-free diet improved the asthma symptoms in 6 of their participants with asthma; possible improvement and no changes were reported in 2 and 8 additional subjects, respectively. In our study, adherence to diet was not correlated with physician-diagnosed asthma or physician-diagnosed allergic rhinitis in 42 patients who were followed for at least one year. Additionally, strict gluten-free diet adherence was neither correlated with asthma symptoms nor with obstructive airway changes.

It has been speculated that the positive association between $C D$ and asthma may result from malnutrition, particularly a vitamin D deficiency (4). We cannot comment on this statement because we regularly screen our patients for vitamin D deficiency and prescribe vitamin D supplements when necessary.

In a cohort study conducted in Italy, it was hypothesized that antibiotic use during the first months of life might lead to the concomitant presence of asthma and CD; however, this link could not be proven (30). In that study, 143,144 children were followed for 16 years, and comorbid asthma and CD were observed in 254 patients. The authors suggested that those diagnosed with asthma were at risk for developing CD but that this correlation was not associated with antibiotic use. Another study implied that because of the 5- to 10-year delay in the diagnosis of $\mathrm{CD}$, the possibility that CD may lead to the development of asthma 
Table 3. The Association of the Follow-up Period of the CD Group with Symptoms of Asthma and Allergic Rhinitis

\begin{tabular}{|c|c|c|c|c|}
\hline & \multicolumn{3}{|c|}{ Follow-Up Period, m } & \multirow[t]{2}{*}{ PValue $^{\mathrm{a}}$} \\
\hline & Mean & SD & Median & \\
\hline \multicolumn{5}{|c|}{ Asthma, $n=53$} \\
\hline Physician-diagnosed asthma & & & & 0.829 \\
\hline Yes & 59.55 & 58.16 & 42 & \\
\hline No & 53.23 & 46.16 & 48 & \\
\hline Wheezing at any time & & & & 0.771 \\
\hline Yes & 47.97 & 41.12 & 36 & \\
\hline No & 57.23 & 51.09 & 60 & \\
\hline Wheezing in the last 12 months & & & & 0.455 \\
\hline Yes & 61.72 & 43.78 & 60 & \\
\hline No & 52.93 & 49.27 & 36 & \\
\hline Exercise-induced wheezing & & & & 0.406 \\
\hline Yes & 61.33 & 43.55 & 60 & \\
\hline No & 53.01 & 49.32 & 36 & \\
\hline Current use of asthma medication & & & & 0.820 \\
\hline Yes & 48.58 & 44.05 & 36 & \\
\hline No & 56.33 & 49.72 & 54 & \\
\hline Nighttime coughing & & & & 0.476 \\
\hline Yes & 43.50 & 46.56 & 36 & \\
\hline No & 56.62 & 48.62 & 54 & \\
\hline \multicolumn{5}{|c|}{ Allergic Rhinitis, $n=53$} \\
\hline Allergic rhinitis & & & & 0.941 \\
\hline Yes & 51.61 & 41.60 & 48 & \\
\hline No & 56.00 & 51.89 & 42 & \\
\hline Allergic rhinoconjunctivitis & & & & 0.505 \\
\hline Yes & 44.79 & 40.83 & 36 & \\
\hline No & 57.89 & 50.48 & 60 & \\
\hline Physician-diagnosed allergic rhinitis & & & & 0.464 \\
\hline Yes & 66.00 & 51.61 & 60 & \\
\hline No & 53.21 & 48.13 & 42 & \\
\hline Nasal steroid use (> 2 weeks) & & & & 0.809 \\
\hline Yes & 54.32 & 46.78 & 36 & \\
\hline No & 54.45 & 48.99 & 48 & \\
\hline
\end{tabular}

${ }^{\mathrm{a}}$ Mann-Whitney U test.

cannot be completely excluded $(31,32)$. A cohort study that examined the association between $\mathrm{CD}$ and asthma from a different perspective found no increased risk of asthma in the children of parents diagnosed with $\mathrm{CD}$ (33). A different case-control study conducted in Italy concluded that CD is not associated with atopy (34).
Of the participants diagnosed with CD in our study, approximately $25 \%$ were underweight, $5 \%$ were overweight, and $2 \%$ were obese according to their BMIs. A previous studies suggested that contrary to common belief, obesity is increasing in patients with CD (35). The rate of adherence to a gluten-free diet was approximately $75 \%$ and, as 
Table 4. The association of dietary adherence with asthma and allergic rhinitis in CD patients being followed for at least one year and undergoing a PFT evaluation

\begin{tabular}{|c|c|c|c|}
\hline \multirow[t]{2}{*}{ Asthma Symptoms and PFT, Obstructive Changes } & \multicolumn{2}{|c|}{ Adherence to Diet, No. (\%) } & \multirow[t]{2}{*}{ PValue $^{\mathbf{a}}$} \\
\hline & Yes, $31(74 \%)$ & No, $22(26 \%)$ & \\
\hline \multicolumn{4}{|c|}{ Asthma } \\
\hline Physician-diagnosed asthma & $7(23)$ & $1(9)$ & 0.657 \\
\hline Wheezing at any time & $10(32)$ & $3(27)$ & 1.000 \\
\hline Wheezing in the last 12 months & $6(19)$ & $2(18)$ & 1.000 \\
\hline Exercise-induced wheezing & $7(23)$ & $2(18)$ & 1.000 \\
\hline Current use of asthma medication & $8(26)$ & $3(27)$ & 1.000 \\
\hline Nighttime coughing & $5(16)$ & $2(18)$ & 1.000 \\
\hline PFT (obstructive changes) & $4(13)$ & $1(9)$ & 1.000 \\
\hline \multicolumn{4}{|c|}{ Allergic Rhinitis } \\
\hline Allergic rhinitis & $11(36)$ & $5(46)$ & 0.720 \\
\hline Physician-diagnosed allergic rhinitis & $4(13)$ & $1(9)$ & 1.000 \\
\hline Allergic rhinoconjunctivitis & $7(23)$ & $4(36)$ & 0.437 \\
\hline Nasal steroid use, $>2$ weeks & $7(23)$ & $3(27)$ & 1.000 \\
\hline
\end{tabular}

${ }^{\mathrm{a}}$ Fisher's exact test.

expected, the rate of slowed growth in those who adhered to the diet was similar to that in those who did not. In addition, approximately $50 \%$ of the participants reported being exposed to cigarette smoke, which suggests that passive smoking remains a significant public health issue despite many deterrent measures.

\subsection{Study Strengths and Limitations}

To the best of our knowledge, this is the first study to apply PFTs and the ISAAC questionnaire in children with CD. Data from our study serve as baseline data for the prevalence of allergic diseases among children with CD and can be compared with future studies. However, our study had a number of limitations. The sample may not reflect the general CD patient population. Additionally, despite the use of standardized questionnaires, the given responses were affected by the patients' educational levels and awareness of their disease. Other limitations include the short follow-up period of some patients, the $26 \%$ rate of non-adherence to a gluten-free diet, and the small sample size.

In conclusion, the prevalence rates of asthma and allergic rhinitis in patients with CD were not significantly higher when compared to controls. There was no association between asthma and allergic rhinitis symptoms and patient adherence to diet or the length of the follow-up period in $C D$ patients.

\section{Acknowledgments}

We wish to thank the children with $\mathrm{CD}$ and their families for taking part in this study.

\section{Footnote}

Authors' Contribution: Sebnem Ozdogan designed and analyzed the data, wrote the manuscript, and acted as the corresponding author. Merve Usta and Nuray Uslu Kizilkan collected the data. Nafiye Urganci helped to evaluate and edit the manuscript and performed a critical revision. All authors read and approved the final manuscript.

\section{References}

1. Husby S, Koletzko S, Korponay-Szabo IR, Mearin ML, Phillips A, Shamir R, et al. European Society for Pediatric Gastroenterology, Hepatology, and Nutrition guidelines for the diagnosis of coeliac disease. J Pediatr Gastroenterol Nutr. 2012;54(1):136-60. doi: 10.1097/MPG.ob013e31821a23do. [PubMed: 22197856].

2. Dalgic B, Sari S, Basturk B, Ensari A, Egritas O, Bukulmez A, et al. Prevalence of celiac disease in healthy Turkish school children. Am J Gastroenterol. 2011;106(8):1512-7. doi: 10.1038/ajg.2011.183. [PubMed: 21691340].

3. Anandan C, Nurmatov U, van Schayck OC, Sheikh A. Is the prevalence of asthma declining? Systematic review of epidemiological studies. Allergy. 2010;65(2):152-67. doi: 10.1111/j.1398-9995.2009.02244.x. [PubMed: 19912154].

4. Akcakaya N, Kulak K, Hassanzadeh A, Camcioglu Y, Cokugras H. Prevalence of bronchial asthma and allergic rhinitis in Istanbul school children. EurJ Epidemiol. 2000;16(8):693-9. [PubMed: 11142496]. 
5. Ones U, Akcay A, Tamay Z, Guler N, Zencir M. Rising trend of asthma prevalence among Turkish schoolchildren (ISAAC phases I and III). Allergy. 2006;61(12):1448-53. doi: 10.1111/j.1398-9995.2006.01145.x. [PubMed: 17073876].

6. Settipane RA. Demographics and epidemiology of allergic and nonallergic rhinitis. Allergy Asthma Proc. 2001;22(4):185-9. [PubMed: 11552666].

7. Duksal F, Akcay A, Becerir T, Ergin A, Becerir C, Guler N. Rising trend of allergic rhinitis prevalence among Turkish schoolchildren. Int J Pediatr Otorhinolaryngol. 2013;77(9):1434-9. doi: 10.1016/j.ijporl.2013.05.038. [PubMed: 23830223]

8. Hood J, Mason AM. Diffuse pulmonary disease with transfer defect occurring with coeliac disease. Lancet. 1970;1(7644):445-7. [PubMed: 4189752].

9. Smith MJ, Benson MK, Strickland ID. Coeliac disease and diffuse interstitial lung disease. Lancet. 1971;1(7697):473-5. [PubMed: 4100350].

10. Berrill WT, Fitzpatrick PF, Macleod WM, Eade OE, Hyde I, Wright R. Bird-fancier's lung and jejunal villous atrophy. Lancet. 1975;2(7943):1006-8. [PubMed: 53495].

11. Robinson TJ. Coeliac disease with farmers' lung. $\mathrm{Br}$ Med J. 1976;1(6012):745-6. [PubMed: 1260308].

12. Karlish AJ. Coeliac disease and diffuse lung disease. Lancet. 1971;1(7708):1077. [PubMed: 4103011].

13. Hodgson HJ, Davies RJ, Gent AE. Atopic disorders and adult coeliac disease. Lancet. 1976;1(7951):115-7. [PubMed: 54635].

14. Tarlo SM, Broder I, Prokipchuk EJ, Peress L, Mintz S. Association between celiac disease and lung disease. Chest. 1981;80(6):715-8. [PubMed: 6101248].

15. Ellul P, Vassallo M, Montefort S. Association of asthma and allergic rhinitis with celiac disease. Indian J Gastroenterol. 2005;24(6):270-1. [PubMed: 16424634].

16. Ludvigsson JF, Hemminki K, Wahlstrom J, Almqvist C. Celiac disease confers a 1.6-fold increased risk of asthma: a nationwide populationbased cohort study. J Allergy Clin Immunol. 2011;127(4):1071-3. doi: 10.1016/j.jaci.2010.12.1076. [PubMed: 21315431].

17. Hemminki K, Li X, Sundquist J, Sundquist K. Subsequent autoimmune or related disease in asthma patients: clustering of diseases or medical care?. Ann Epidemiol. 2010;20(3):217-22. doi: 10.1016/j.annepidem.2009.11.007. [PubMed: 20036578].

18. Kero J, Gissler M, Hemminki E, Isolauri E. Could TH1 and TH2 diseases coexist? Evaluation of asthma incidence in children with coeliac disease, type 1 diabetes, or rheumatoid arthritis: a register study. J Allergy Clin Immunol. 2001;108(5):781-3. doi: 10.1067/mai.2001.119557. [PubMed: 11692104]

19. Simpson CR, Anderson WJ, Helms PJ, Taylor MW, Watson L, Prescott GJ, et al. Coincidence of immune-mediated diseases driven by Th1 and Th2 subsets suggests a common aetiology. A population-based study using computerized general practice data. Clin Exp Allergy. 2002;32(1):37-42. [PubMed: 12002734].

20. Sheikh A, Smeeth L, Hubbard R. There is no evidence of an inverse relationship between TH2-mediated atopy and TH1-mediated autoimmune disorders: Lack of support for the hygiene hypothesis. J Allergy Clin Immunol. 2003;111(1):131-5. [PubMed: 12532108].

21. Tirosh A, Mandel D, Mimouni FB, Zimlichman E, Shochat T, Kochba I. Autoimmune diseases in asthma. Ann Intern Med. 2006;144(12):877-
83. [PubMed: 16785476].

22. Kang JY, Kang AH, Green A, Gwee KA, Ho KY. Systematic review: worldwide variation in the frequency of coeliac disease and changes over time. Aliment Pharmacol Ther. 2013;38(3):226-45. doi: 10.1111/apt.12373. [PubMed: 23782240].

23. Lohi S, Mustalahti K, Kaukinen K, Laurila K, Collin P, Rissanen H, et al. Increasing prevalence of coeliac disease over time. Aliment Pharmacol Ther. 2007;26(9):1217-25. doi: 10.1111/j.1365-2036.2007.03502.x. [PubMed: 17944736].

24. Saraclar Y, Kuyucu S, Tuncer A, Sekerel B, Sackesen C, Kocabas C. Prevalence of asthmatic phenotypes and bronchial hyperresponsiveness in Turkish schoolchildren: an International Study of Asthma and Allergies in Childhood (ISAAC) phase 2 study. Ann Allergy Asthma Immunol. 2003;91(5):477-84. doi:10.1016/S1081-1206(10)61517-7. [PubMed 14692432].

25. Kuczmarski RJ, Ogden CL, Grummer-Strawn LM, Flegal KM, Guo SS Wei R, et al. CDC growth charts: United States. Adv Data. 2000(314):127. [PubMed: 11183293]

26. American Thoracic Society . Standardization of Spirometry, 1994 Update. American Thoracic Society. Am J Respir Crit Care Med. 1995;152(3):1107-36. doi: 10.1164/ajrccm.152.3.7663792. [PubMed: 7663792].

27. Zauli D, Grassi A, Granito A, Foderaro S, De Franceschi L, Ballardini G, et al. Prevalence of silent coeliac disease in atopics. Dig Liver Dis. 2000;32(9):775-9. [PubMed: 11215557].

28. Kurt E, Metintas S, Basyigit I, Bulut I, Coskun E, Dabak S, et al. Prevalence and Risk Factors of Allergies in Turkey (PARFAIT): results of a multicentre cross-sectional study in adults. Eur Respir J. 2009;33(4):724-33. doi: 10.1183/09031936.00082207. [PubMed: 19129285].

29. Kallel-Sellami M, Laadhar L, Zitouni M, Makni S. [Recurrent rhinitis and pulmonary infections revealing celiac disease: case report]. Rev Pneumol Clin. 2008;64(1):27-9. doi: 10.1016/j.pneumo.2008.06.003. [PubMed: 18603176].

30. Canova C, Pitter G, Ludvigsson JF, Romor P, Zanier L, Zanotti R, et al. Coeliac disease and asthma association in children: the role of antibiotic consumption. Eur Respir J. 2015;46(1):115-22. doi: 10.1183/09031936.00185714. [PubMed: 25929947].

31. Rampertab SD, Pooran N, Brar P, Singh P, Green PH. Trends in the presentation of celiac disease. Am J Med. 2006;119(4):9-14. doi: 10.1016/j.amjmed.2005.08.044. [PubMed: 16564784].

32. Norstrom F, Lindholm L, Sandstrom O, Nordyke K, Ivarsson A. Delay to celiac disease diagnosis and its implications for health-related quality of life. BMC Gastroenterol. 2011;11:118. doi: 10.1186/1471-230X-11-118. [PubMed: 22060243]

33. Andersen AB, Erichsen R, Kappelman MD, Froslev T, Ehrenstein V Parental celiac disease and risk of asthma in offspring: a Danish nationwide cohort study. Clin Epidemiol. 2015;7:37-44. doi: 10.2147/CLEP.S73662. [PubMed: 25565892].

34. Greco L, De Seta L, D’Adamo G, Baldassarre C, Mayer M, Siani P, et al Atopy and coeliac disease: bias or true relation?. Acta Paediatr Scand. 1990;79(6-7):670-4. [PubMed: 2386060].

35. Venkatasubramani N, Telega G, Werlin SL. Obesity in pediatric celiac disease. J Pediatr Gastroenterol Nutr. 2010;51(3):295-7. doi: 10.1097/MPG.0b013e3181d1365a. [PubMed: 20479683] 